\title{
Percepção dos Usuários Acerca dos Serviços de Proteção Social Disponibilizados aos Refugiados e/ou Solicitantes de Refúgio na Cidade de São Paulo.
}

Tema 4 ) Questões locais e regionais sobre expansão demográfica, migração e ambiente.

GAMBARDELLA, A.D.* (alicedigam@gmail.com); ASSIS, F.R. **

(flaviaribeirodeassis@gmail.com); ZOÉGA, M.*** (magazoega@yahoo.com.br)

CORÁ, M.A.J.**** (mcora@ pucsp.br)

* Doutora em Serviço Social (PUC/SP), pesquisadora Pós-doc vinculada Núcleo de Estudos e Pesquisas em Política Social - Programa de Pós-Graduação em Serviço Social da Universaide Federal da Paraíba.

** Coordenadora de Programas e Projetos na United Way Brasil.

*** Co-fundadora do Coletivo Conviva Diferente - Centro de Integração da Cidadania do Imigrante (CIC Imigrante).

**** Pós-Doutora em Sociologia (PUC-SP), professora da Pontifícia Universidade Católica de São Paulo/Programa de Administação.

Resumo: O presente trabalho tem por objetivo analisar os serviços de atendimento oferecidos na cidade de São Paulo aos refugiados e/ou imigrantes. Para atingir tal propósito efetuou-se um levantamento bibliográfico para contextualizar a história da imigração no Brasil; realizouse um mapeamento de todos os serviços oferecidos a esse público na cidade de São Paulo e; por fim foram entrevistados 24 refugiados, de seis nacionalidades diferentes, por meio de uma entrevista semiestruturada para conhecimento a respeito da percepção desses sujeitos quanto aos serviços que lhe são oferecidos. Após análise dos discursos, foram listados aqueles mencionados espontaneamente pelos entrevistados, bem como a qualidade a eles atribuída. Os resultados indicaram que, em sua maioria, os serviços são bons, mas que ainda há barreiras a serem transpostas, tais como: a falta de funcionários com domínio de outro idioma; a dificuldade de se ter acesso a determinadas informações e, também, o baixo conhecimento da sociedade em geral sobre a condição do refugiado. Concluiu-se com base no processo histórico, no mapeamento e nos relatos dos entrevistados que o Brasil evoluiu no quesito acolhimento e atendimento ao refugiado, tendo como prova os inúmeros serviços oferecidos na cidade de São Paulo a esse público, todavia ainda carente de algumas transformações. Percebeu-se ainda que a cidade de São Paulo pode vir a ser uma referência de destino para os refugiados e imigrantes que chegam ao Brasil, por se tratar da maior do país, porém, como metrópole, precisa percorrer um logo caminho para assegurar que os direitos dos refugiados sejam respeitados e exercidos, muito embora a direção pareça acertada e incrementos aumentados em relação aos investimentos do passado recente.

Palavras-Chave: refugiado, imigração, serviços de atendimento aos refugiados. 


\section{INTRODUÇÃO}

Basta uma simples consulta nos diários, nacionais ou internacionais, para se deparar com a realidade migratória em âmbito global. Diariamente milhares de pessoas deixam e/ou tentam deixar seus países de origem, os quais assolados por guerras civis, guerrilhas, ataques terroristas, opressões religiosas entre outros fatores tornam sua nação "inabitável”. Neste sentido, Mendes (2013, p. 47) destaca que:

A migração internacional está ligada às enormes desproporcionalidades existentes entre os países, agravadas principalmente pelas assimetrias e crises econômicas apresentadas por países de baixo desenvolvimento. Se no país de origem as dificuldades econômicas fazem aumentar a pobreza e a marginalização, então as correntes migratórias se orientam na direção de países nos quais existam maiores oportunidades de emprego e investimentos. Ainda assim, mesmo que haja crescimento econômico em determinado país, a insuficiente geração de empregos contribui para a migração de pessoas em busca de melhores condições de vida. Outro indicador importante é que a migração tem entre suas complexas causas a existência de fatores políticos referentes a desigualdades sociais, conflitos étnicos, religiosos, desastres naturais, etc.

Segundo as Nações Unidas e a Organização para a Cooperação e o Desenvolvimento Econômico (OCDE) no ano de 2013 existia no mundo "aproximadamente 232 milhões de migrantes internacionais. Desde 1990, o número de migrantes internacionais no Norte global aumentou cerca de 53 milhões (65\%), contra um aumento de cerca de 24 milhões (34\%) no Sul global” (OCDE, 2013, p. 1). É possível constatar que este aumento mundial também é refletido em âmbito nacional, como os dados disponibilizados pelo Instituto Brasileiro de Geografia e Estatística' (IBGE, 2012, p. 15-16) revelaram que: "O número de imigrantes internacionais do Brasil passou de 143 mil entre 1995 e 2000 para 268 mil entre 2005 e 2010. Entre os imigrantes internacionais que chegaram ao Brasil entre 1995 e 2000, 61\% eram brasileiros, ou seja, imigrantes internacionais de retorno."

Dentre os imigrantes internacionais que chegam ao país atualmente, quem são os refugiados e quais os seus direitos? No Brasil, o órgão responsável por analisar os pedidos de

\footnotetext{
1 Sobre os dados divulgados pelo IBGE, o analista Marden B. Campos apresenta uma série de considerações quantos aos resultados, para maiores informações, Ver: CAMPOS, M. B. A imigração para o Brasil segundo o Censo Demográfico 2010. Caderno de Debates Refúgio, Migrações e Cidadania, Brasília: Instituto Migrações e Direitos Humanos, v. 7, n. 7, p. 15-20, 2012.
} 
refúgio e declarar o reconhecimento, em primeira instância, da condição de refugiado é o Comitê da Organização das Nações Unidas (ONU) para Refugiados (CONARE), criado pela lei 9.474, de 1997. A lei garante documentos básicos aos refugiados, incluindo documento de identificação e de trabalho, além da liberdade de movimento no território nacional e de outros direitos civis (ACNUR, 2014).

Para um estrangeiro obter refúgio no país, ele precisa demonstrar "fundados temores" de perseguição por motivos de raça, religião, nacionalidade, grupo social ou opiniões políticas. O solicitante ao benefício também pode alegar generalizada violação dos direitos humanos em seu país de origem, como, por exemplo, guerras. Uma vez concedido o refúgio, o estrangeiro pode viver em definitivo e trabalhar legalmente no Brasil. Os direitos se estendem a cônjuges, filhos, pais e outros integrantes da família que dependam economicamente do refugiado. Enquanto o pedido é analisado, o solicitante recebe um protocolo e, de posse desse documento, consegue trabalhar regularmente no Brasil. O número de pedidos de refúgio no Brasil, como demonstrado no Gráfico 1, abaixo, “entre 2010 e 2013 aumentou 930\% (de 566 para 5.882). Até outubro de 2014 foram 8.302" (PASSARINHO, 2014, s. p). A maioria dos pedidos ocorreu no estado de São Paulo, com $26 \%$ do total. Regionalmente, as maiores concentrações estão no Sul, com 35\% e no Sudeste, com $31 \%$ (ACNUR, 2014).

Conforme dados do Comitê da Organização das Nações Unidas (ONU) para Refugiados (CONARE) de 2014 divulgados pela Agência da ONU para Refugiados, por meio do Alto Comissariado das Nações Unidas para Refugiados (ACNUR), o Brasil possui 7.289 refugiados de 81 nacionalidades, sendo os principais provenientes da Síria, Colômbia, Angola, República do Congo, Senegal, Gana e Nigéria. Este perfil vem mudando desde 2012 devido a Portaria 2.650 de outubro de 2012, do Ministério da Justiça que contém cláusula de cessação de refúgio para angolanos e liberianos, os quais atualmente estão recebendo residência permanente no país. A Resolução nº 17 de 20 de setembro de 2013, também do CONARE, facilita a entrada de sírios no Brasil emitindo vistos por razões humanitárias pelo prazo de 2 anos, podendo ser prorrogado. Os colombianos também se beneficiam de entrada facilitada graças a adesão da Colômbia ao Acordo de Residência do MERCOSUL, o qual lhes concedem residência temporária no país por dois anos. Além das nacionalidades supracitadas, o país vem recebendo um grande fluxo de imigrantes haitianos, desde o terremoto que assolou o país em janeiro de 2010. Apesar de solicitarem o reconhecimento da condição de refugiados ao entrarem em território nacional, seus pedidos são encaminhados ao Conselho Nacional de 
Imigração (CNIg), que emitiu vistos de residência permanente por razões humanitárias. De acordo com dados da Polícia Federal, mais de 39.000 haitianos entraram no Brasil desde 2010 até 2014 (ACNUR,2014).

Gráfico 1 Novas solicitações de refúgio (por ano)

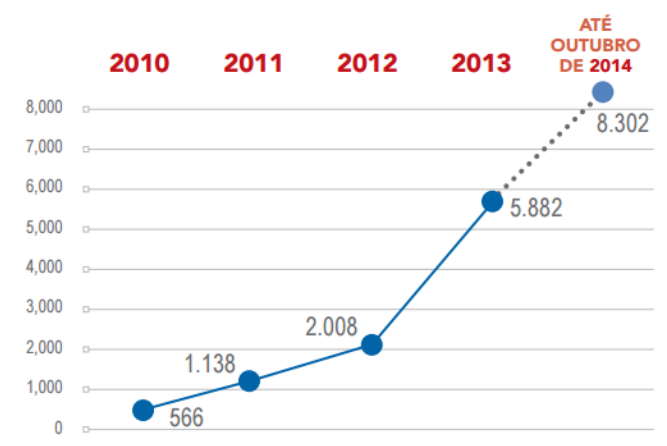

Fonte: Extraído de ACNUR (2014, p. 1).
Gráfico 2 Número de refugiados reconhecidos no Brasil (por ano)

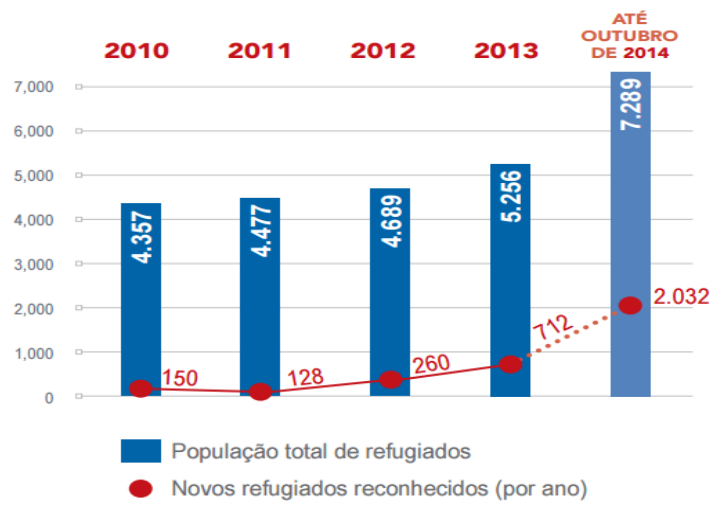

Fonte: Extraído de ACNUR (2014, p. 1).

De acordo com o mesmo relatório, como expressado no Gráfico 2, a seguir:

[...] o número de refugiados reconhecidos [também] aumentou expressivamente no período mencionado. Em 2010, 150 refugiados foram reconhecidos pelo CONARE, enquanto em 2014 (até outubro), houve 2.032 deferimentos pelo Comitê, o que representa um crescimento aproximado de 1.240\%. Desta forma, apesar de haver se mantido estável de 2010 a 2012 (em torno de 4.000), a população de refugiados no Brasil vem crescendo de forma acelerada entre 2013 e 2014 (até outubro), quando atingiu 5.256 e 7.289 indivíduos, respectivamente (ACNUR, 2014, p. 1).

No ano de 2011, enquanto as organizações humanitárias que lidam com o complexo problema dos refugiados se preparavam para comemorar os 60 anos da Convenção sobre o Estatuto dos Refugiados de 1951, o mundo convulsionava por causa de uma série de conflitos bélicos. Seu impacto humanitário não pode ser mensurado apenas em números de pessoas forçadamente deslocadas, tampouco em número de mortos ou feridos (RAMIREZ, 2012, p.7). 
Além dos conflitos na Síria, amplamente divulgados pela mídia, vários outros se arrastam por anos no continente africano e parecem estar longe de um processo de pacificação. O panorama geral dos conflitos que assolam os principais países de origem dos solicitantes de refúgio e refugiados africanos não será apresentado neste trabalho, pois além da sua exposição não estar incluída no objetivo deste, sua complexidade, dimensão do continente, com milhares de etnias e diferentes processos históricos pós-colonialismo europeu de cada país, mereceriam outro estudo aprofundado. Entretanto, será contemplado no item "Motivos para Migração", segundo capítulo, um breve resumo do que ocorre atualmente na Nigéria, República do Congo e Angola, países de procedência de 50\% dos participantes entrevistados nos instrumentos de coletas de dados para este trabalho.

Para atender a crescente demanda de refugiados e imigrantes no Estado de São Paulo, algumas instituições se destacam no acolhimento e/ou atendimento desses indivíduos. As principais são: Centro de Referência para Refugiados da Caritas Arquidiocesana de São Paulo $^{2}$; Instituto de Reintegração do Refugiado $\left(\mathrm{ADUS}^{3}\right)$ e o Centro de Referência e Acolhida para o Imigrante da Prefeitura de São Paulo (CRAI).

Mas como será que essas e todas as outras instituições na cidade de São Paulo lidam com essa crescente onda de imigrantes e refugiados? Com base nesses elementos a presente investigação teve por objetivo pesquisar as instituições da cidade de São Paulo destinadas ao acolhimento e/ou atendimento desses imigrantes e/ou refugiados, de modo a permitir sua percepção acerca dos serviços municipais e/ou estaduais, considerando também as Organizações Não Governamentais (ONGs) de atenção ao seu solicitante.

\section{PROCEDIMENTOS, PERCEPÇÕES E O CAMPO}

A presente pesquisa pautou-se em um método qualitativo a partir de técncias de estudos de caso associadas à história oral. Utilizou-se roteiro de entrevistas estruturadas, aplicadas à refugiados e/ou imigrantes socilitantes de refúgio.

\footnotetext{
2 “é um projeto da Caritas Arquidiocesana de São Paulo realizado na sede da Caritas no centro de São Paulo que tem como objetivo o apoio na integração e proteção de solicitantes de refúgio e refugiados na cidade de São Paulo" (CARITAS, 2014). Cf. CARITAS. O Centro de Referências para Refugiados. Caritas Arquidiocesana de São Paulo, 2014. Disponível em: <http://www.caritassp.org.br/?page_id=85>. Acesso em: 29 maio 2016.

3 "foi fundado, em 2010, por 3 amigos internacionalistas e pesquisadores do tema do refúgio, o Adus - Instituto de Reintegração do Refugiado. Desde então, realizamos diversas ações voltadas à conscientização, diminuindo os casos de preconceito contra essas pessoas; diversos postos de trabalho foram criados; vagas em cursos foram logradas; muitos voluntários foram incluídos ao nosso grupo de colaboradores e contribuem Efetivamente em nossas ações e projetos. Solicitantes de refúgios e refugiados passaram a ter voz" (ADUS, 2015). Cf.: ADUS INSTITUTO DE REINTEGRAÇÃO DO REFUGIADO. Sobre nós: histórico. ADUS, 2015. Disponível em: <http://www.adus.org.br/sobre-nos/historico/>. Acesso em: 29 maio 2016.
} 
Para efetuação das investigações, foram realizados os seguintes procedimentos: contato com a instituição; contato com os participantes; agendamento e realização das entrevistas; tabulação dos resultados e análise dos dados. Concernente ao mapeamento, este foi realizado pautado no levantamento bibliográfico, experiência das pesquisadoras e análise do referencial teórico. Cumpre mencionarmos que o relatório elaborado e publicado em 2015, sob a coordenação da pesquisadora Liliana Lyra Jubilut, intitulado: Migrantes, apátridas $e$ refugiados: subsídios para o aperfeiçoamento de acesso a serviços, direitos e políticas públicas no Brasil, foi tomado como referência não apenas para o mapeamento dos serviços como para análise dos resultados da presente investigação, principalmente quanto aos resultados obtidos pelos pesquisadores no estado de São Paulo.

As entrevistas foram realizadas com seis grupos de indivíduos, de diferentes nacionalidades, todos afrodescendentes, vindos da Nigéria, Mali, Serra Leoa, República Democrática do Congo, Angola e Haiti. Cada grupo está representado por quatro sujeitos: um do sexo feminino e três do masculino. Com exceção do grupo do Mali, composto apenas por três homens, e o grupo da Nigéria contemplado por quatro homens e uma mulher, nos demais grupos, ou seja, Serra Leoa, República Democrática do Congo, Angola e Haiti tem-se três homens e uma mulher.

Com relação ao Mali, optou-se pela entrevista de apenas três indivíduos do sexo masculino, pois, conforme relato dos integrantes que se encontravam no local na ocasião da entrevista, aquela comunidade é frequentada por aproximadamente 60 pessoas, sendo apenas uma do sexo feminino. Assim, considerou-se que para além da dificuldade de estabelecer contato, seria irrelevante, diante do número total de malineses, a aplicação do questionário a uma pessoa do sexo feminino. Por outro lado, frente ao grande número de nigerianos do sexo masculino encontrados durante as entrevistas, optou-se por compensar a ausência feminina do Mali por mais um indivíduo do sexo masculino da Nigéria. Assim, as entrevistas foram efetuadas com cinco nigerianos (quatro homens e uma mulher), três malineses (sexo masculino), quatro congoleses, quatro leoneses, quatro angolanos e quatro haitianos, totalizando, assim 24 participantes.

Os locais visitados para as entrevistas foram: Centro de Integração da Cidadania do Imigrante (CIC Imigrante), situado na Rua Barra Funda, 1.020, onde se entrevistou cinco nigerianos, quatro leoneses, dois congoleses e dois haitianos; Missão Paz, localizada na Rua do Glicério, 225, com entrevistas de dois angolanos e um haitiano; nos Estabelecimentos comerciais, aos arredores da Missão Paz com uma haitiana, dois angolanos e um congolês; 
Sindicomunitário, Av. Prestes Maia, 241, Conjunto 4301 onde se entrevistamos uma congolesa; na Comunidade do Mali, Rua Visconde de Parnaíba, 1117 com três malineses entrevistados.

\section{PERFIL DOS PARTICIPANTES}

Participaram desta pesquisa 24 refugiados, distribuídos em seis grupos, de distintas etnias. Somente como guisa de observação destacamos que atualmente os haitianos solicitantes de refúgio no Brasil recebem visto humanitário, como explicamos no primeiro capítulo, estes não são considerados pelo CONARE como refugiado.

Quadro 1 Perfil dos participantes da pesquisa

(continua...)

\begin{tabular}{|c|c|c|c|c|c|}
\hline \multicolumn{6}{|c|}{ Caracterização dos participantes da pesquisa } \\
\hline Sexo & Origem & Id. Oficial & Idioma falado & Etnia & Chegada \\
\hline $\mathrm{F}$ & Angola & Port. & $-*$ & $-* *$ & 2016 \\
\hline M & Angola & Port. & Fr & Cabindiano & 2016 \\
\hline M & Angola & Port. & Port., Ing., Fr. & Quimbue & 2015 \\
\hline M & Angola & Port. & Fr., Ing. & Kinbundo & 2015 \\
\hline M & Haiti & Criolo, Fr. & - & - & 2014 \\
\hline $\mathrm{F}$ & Haiti & Criolo, Fr & Fr., Ing., Por. & Criolo & 2014 \\
\hline M & Haiti & Fr., Criolo & Fr. Criolo, Ing., Esp., Port. & - & 2015 \\
\hline M & Haiti & Criolo, Fr. & Fr., Criolo, Igl. & - & 2014 \\
\hline M & Mali & Fr. & Fr. & Bambara & 2014 \\
\hline $\mathrm{F}$ & Mali & Fr. & Fr. & Soninke & 2015 \\
\hline M & Mali & Fr. & Fr., Arb., Ing., Port. & Soninke & 2014 \\
\hline M & Nigéria & Igbo, Ing. & - & Igbo & 2014 \\
\hline M & Nigéria & Ing. & Ing. e Igbo & Igbo & 2014 \\
\hline & & & & & (conclusão) \\
\hline \multicolumn{6}{|c|}{ Caracterização dos participantes da pesquisa } \\
\hline Sexo & Origem & Id. Oficial & Idioma falado & Etnia & Chegada \\
\hline M & Nigéria & Ing. & Igbo & Igbo & 2015 \\
\hline M & Nigéria & Ing. & Port., Igbo, Hausa, Bacharma & Igbo & 2015 \\
\hline $\mathrm{F}$ & Nigéria & Ingl. & Igbo, Ing. e Yoruba & Igbo & 2015 \\
\hline M & R. D. Congo & Fr. & Fr., Port. & Mukongo & 2014 \\
\hline M & R. D. Congo & Fr. & Fr., Port. & Bakongo & 2015 \\
\hline M & R. D. Congo & Fr. & Lingala & - & $-* * *$ \\
\hline $\mathrm{F}$ & R. D. Congo & Fr. & Fr., Lingala, Port. & - & 2014 \\
\hline $\mathrm{F}$ & Serra Leoa & Ing. & Ing. & Fula & 2014 \\
\hline M & Serra Leoa & Ing., Fr. & Ing. & Kimla & 2016 \\
\hline M & Serra Leoa & Ing. & Port. (basic.) & Mende & 2014 \\
\hline M & Serra Leoa & Ing. e krio & Krio e outros dialetos $* * * *$ & Temin & 2016 \\
\hline
\end{tabular}

Legenda: $\mathrm{M}$ = masculino; $\mathrm{F}$ = feminino; Id. = idioma; R.D Congo = República Democrática do Congo; Fr. = francês; Port.= português; Ing. = Inglês; Esp. = espanhol; Arb. = Árabe. 
Notas: -* indica informação ausente, todavia supomos com base no idioma oficial que o participante fala pelo menos o idioma ou um deles, no caso de países com mais de um idioma oficial.; -** etnia não informada pelo participante; -*** data de chegada ao Brasil não declarada; -**** Lingala, Kikongo, Kiombe, Swahili (dialetos).

Dos 24 entrevistados, 19 chegaram ao Brasil de avião, quatro declararam que vieram de navio e um não precisou como chegou ao país, para qual deduzimos que utilizou mais de um meio de transporte. Assim como, 16 deles afirmaram ter filhos e oito deles não possuem rebento. Quanto à família, seis deles vieram com a mesma enquanto 16 deixaram seus familiares no país de origem, e dois responderam que fizeram a viagem com outras pessoas. Constatamos que a maioria pretende trazer a família para o Brasil $(n=19)$, assim como 21 deles pretendem ficar no país, dois declararam não almejar ficar e um ainda não se decidiu. Atualmente, somente oito deles estão trabalhando, dos quais seis exercem atividades formais, ou seja, com carteira assinada, os outros dois executam atividades informais. Todavia, percebermos que os entrevistados portam a Carteira de Trabalho.

Referente à chegada ao Brasil, constatamos que a maioria chegou entre 2014 e 2016, sendo que nove chegaram em 2014, dois vieram no primeiro semestre de 2015, seis no segundo semestre do mesmo ano e quatro chegaram em 2016. Destacamos que três entrevistados não determinaram o ano de chegada.

Concernente à moradia, sete deles estão alocados em abrigos temporários (Casa do Migrante; CRAI; Igreja e um abrigo na Luz) e 17 residem em diferentes bairros de São Paulo, os quais podem ser agrupados em: região central da cidade, zona leste e zona sul. Como veremos mais adiante, essa aglomeração nas regiões citadas pode ser explicada pela oferta de serviços de atendimento nessas regiões, pois foi constatado que esses bairros compreendem maior número de serviços ofertados.

Supomos também que esse processo de aglomeração pode estar atrelado à formação de pequenas comunidades, "guetos" de refugiados, pois percebemos, por exemplo, que algumas regiões são frequentadas por grupos de diversas etnias, por exemplo, a região da baixada do Glicério, onde está situada a Missão Paz que acolhe os refugiados - haitianos em sua maioria - assim como citamos anteriormente uma matéria que mencionava a transformação do cenário de um bairro em Guaianases (FOLHA DE S. PAULO, 2015a).

Referentes à educação, dois possuem ensino médio incompleto, 11 declararam ter ensino médio completo, quatro ensino superior incompleto e sete com ensino superior 
completo. Evidenciamos que quase metade dos participantes concluiu o ensino médio, situação essa que de certa forma interfere em sua colocação no mercado formal, o que também não é assegurado aos detentores de ensino superior completo. Por conta da recente crise econômica e política brasileira, uma parcela dos refugiados deixaram de considerar o país como uma boa opção migratória, como vinculado pela Folha de S. Paulo (2016) Para fugir da crise, haitianos trocam o Brasil pelo Chile. Esse fato é refletido no número de entrevistados que estavam trabalhando na ocasião das entrevistas. Entre as ocupações profissionais no país de origem, temos: ajudante geral, autônomo, cabeleireira, carreteiro, comerciante, estudante, estivador, eletricista, encanador, jornalista, jogador de futebol, motorista, pastor, professor de idiomas, pintor, taxista e vendedor.

Por fim, chegamos ao motivo da/para migração, sete afirmaram que a motivação para deixar seu país de origem foi a guerra, cinco saíram por questões políticas, três por causa do desemprego, um saiu por conta do trabalho missionário, um por razão da ditadura (o que a nosso entender pode ser compreendido como motivo político), outro devido ao ebola e seis alegaram outros motivos. Considerando a guerra um motivo de proeminência mundial, abordamos a questão no próximo item.

\section{MOTIVOS PARA MIGRAÇÃO}

Sabe-se que as catástrofes naturais também provocam grandes fluxos migratórios, como no caso do terremoto que atingiu o Haiti e deixou milhares de pessoas mortas e outros milhares de desabrigados. Contudo o duo violência/guerra e catástrofe natural seguem deixando seu rastro de vítimas, homens, mulheres e crianças de todas as raças e cores, algumas sofrendo mais que outras. As regiões da África e do Oriente Médio, que estão sob ataque, atualmente controladas por grupos terroristas são as mais afetadas.

Na Nigéria, os conflitos são decorrentes de ataques praticados pelo grupo Boko Haram. O grupo é predominantemente associado ao fundamentalismo islâmico, em que atos de violência seriam efetuados por jihadistas - ainda que o termo tenha múltiplos significados que teriam por objetivo a imposição da estrutura estatal baseada na "sharia", ou seja, o código moral e Direito Islâmico (Wenczenovicz, T.J. 2014).

Atuando no nordeste da Nigéria e em países fronteiriços, como Camarões, Chade e Níger, o Boko Haram dissemina suas práticas violentas, como o sequestro de 200 mulheres em 2014, tráfico de armas, ataques a civis em instituições religiosas cristãs, saques a bancos, 
delegacias e bases militares, e por tais práticas, o grupo é responsável pelo deslocamento das pessoas naquela região, o que diminui a produção e dificulta o acesso a alimentos, agravando a situação. De acordo com dados disponiblizados pela ONU, o Boko Haram é responsável pelo deslocamento de 1,4 milhões de crianças refugiadas (ONUBR, 2015).

Já na República Democrática do Congo, desde 1996, províncias do leste do país, destacando-se Kivu do Sul e Kivu do Norte, têm seus conflitos desencadeados por rebeliões locais com motivações étnicas e territoriais. Esses conflitos mascaram disputas pelo controle de recursos minerais por milícias e estados da região. Segundo relatório do Enough Project, os grupos armados que lucram com a exploração e comércio de minerais no leste do Congo cometem atrocidades pelo controle de minas, rotas de transporte e oportunidades de extorquir os envolvidos neste tipo de transações. Os principais metais em questão são o estanho, o tântalo, o tungstênio e o ouro, sendo os três primeiros utilizados na produção de eletrônicos. Para a organização, a superação do conflito requer abordagem compreensiva que envolva investimento de longo prazo, segurança, governança e meios de sobrevivência para a população (ENOUGH PROJECT, 2009). Segundo o International Rescue Committee, até 2007, o conflito havia causado 5,4 mlhões de mortes, enquanto a Agência da ONU para Refugiados divulgou o número de mais de 2,6 milhões de deslocamentos internos e 535 mil refugiados até 2015 (ACNUR, 2015).

Angola, por sua vez, mesmo tendo adotado o regime presidencialista após sua independência de Portugal em 1975, ainda encontra muitos obstáculos para conseguir a consolidação da democracia. A independência foi proclamada um ano após a queda do regime ditatorial português de Antônio de Oliveria Salazar pelos três maiores partidos da época: Movimento Popular de Libertação de Angola (MPLA), Frente Nacional de Libertação de Angola (FNLA) e União Nacional para Independência Total de Angola (UNITA). Quando Portugal perdeu o controle sobre a colônia, esses três partidos passaram a disputar o governo da nova república, o que, com o apoio das potências da Guerra Fria, acabou resultando na Guerra Civil de Angola, que durou até 2002, deixando milhares de vítimas. A Organização das Nações Unidas (ONU) estima que houve mais de 4 milhões de deslocados internos e cerca de 600 mil refugiados oriundos desta guerra (ONUBR, 2012).

Desde então e por razões de proximidade línguística e cultural, o Brasil já figurava como destino de diversos angolanos. Em 2012, o Alto Comissariado das Nações Unidas para Refugiados (ACNUR) adotou uma cláusula de cessação, determinando que os angolanos que tivessem deixado seu país por motivo da guerra de independência com Portugal (1965/75) ou 
da guerra civil (1975/2002) não seriam mais considerados refugiados, pois o país já havia alcançado a "paz e a estabilidade" após dez anos do fim dos conflitos. No entanto, tal cláusula não deve ser aplicada aos indivíduos que deixaram ou deixam o país após 2002, uma vez que a instabilidade que se seguiu após o término da guerra civil ainda obriga os angolanos a solicitarem refúgio em outros países.

Em suma, pode-se entender que o principal motivo migratório é a ameaça à integridade física, à vida, à existência do ser humano, pois se o país de origem oferecesse aos migrantes a oportunidade de viver de forma íntegra, poucos teriam motivos para deixá-lo.

\section{ONDE PROCURA AJUDA}

Podemos assegurar que o primeiro contato a ser realizado ao chegar ao país é com a Polícia Federal, o que não poderia ser diferente, pois é responsável por checar as pessoas que entram no país. Quando uma pessoa de outra nacionalidade entrar em território brasileiro por vias legais, sejam aéreas, marítimas ou térreas deparar-se-á com um posto de atendimento da Polícia Federal. Consideramos que há possibilidade de entrar ilegal e clandestinamente no Brasil, todavia mesmo que seja este o caso deve-se procurar a Polícia Federal para informar sua condição, preencher o protocolo de solicitação de refúgio e aguardar decisões subjacentes. Impreterivelmente, não se deve omitir o fato, pois ao permanecer como ilegal no país, sem qualquer registro de entrada e documentação válida é possível ser impedido de permanecer no Brasil, pois a ilegalidade causará transtornos ao imigrante como em qualquer outro país.

Após o primeiro contato com a Polícia Federal o ingressante no país na condição de migrante ou refugiado pode acessar qualquer um dos serviços públicos assegurados ao cidadão brasileiro, no quesito segurança, saúde, educação entre outros. Portanto, pode adquirir Carteira de Trabalho no Ministério do Trabalho, bem como cartão de saúde para ser atendido nos postos de saúde, hospitais entre outros equipamentos disponibilizados pelo Sistema Único de Saúde Brasileiro (SUS) e, se o refugiado tiver consigo os filhos deve providenciar sua matrícula em uma escola do sistema público.

Além dos serviços estatais, federais e municipais oferecidos há também as ações promovidas pela sociedade civil, tais como: curso de português para imigrantes e/ou refugiados - boa parte deles gratuitos; cursos profissionalizantes; entre outros. 
Os principais serviços prestados e citados pelos imigrantes e/ou refugiados são listado por nome e localização na cidade de São Paulo: Centro de Apoio e Pastoral do Migrante, Alameda Nothmann, 485; Centro de Direitos Humanos e Cidadania do Imigrante (CDHIC), Rua Bernardo Magalhães, 203, Tatuapé; CRAI - Centro de Referência e Acolhida do Imigrante, Rua Japura, 234, Bela Vista; Defensoria Pública da União, Rua Fernando de Albuquerque, 155 Consolação; Delegacia Polícia Federal Santos, Rua Riachuelo 27, Centro, Santos $^{25}$; Delegacia de Polícia Federal - Guarulhos, GRU Airport Terminal 3; Delegacia de Polícia Federal - São Paulo, R. Hugo Dantola, 95 - Lapa; Instituto de Reintegração do Refugiado (ADUS), Av. São João, 313, 11 Andar, Centro; Instituto Terra, Trabalho e Cidadania (ITTC), R. Marquês de Itu, 298 - Vila Buarque; Ministério do Trabalho e Emprego, Rua Martins Fontes, 109, sala 806; Ministério Público Federal, Rua Frei Caneca, 1360; Procuradoria da República, Av. Brigadeiro Luís Antônio, 2020; Secretaria de Desenvolvimento Social, Rua Bela Cintra, 1032, Cerqueira Cesar; Secretaria de Saúde, Av. Dr. Eneas Carvalho de Aguiar, 188, $5^{\circ}$ andar; Bibliaspa - Biblioteca e Centro de Pesquisas da América do Sul-Países Árabes-África, Rua Baronesa de Itu, 639, Sta Cecília; CIC ImigranteCentro de Integração da Cidadania do Imigrante, Rua Barra Funda, 1020; CIEE - Centro de Integração Empresa Escola, Rua Maria Paula, 212, Centro; Centro de Direitos Humanos e Cidadania do Imigrante (CDHIC), Rua Bernardo Magalhães, 203, Tatuapé; Cáritas Arquidiocesana de São Paulo, Rua José Bonifácio, 107, Centro. O Mapa 1, abaixo indica todos os serviços encontrados no levantamento e listados e está disponível no Google Maps.

Mapa 1 Indicação dos locais de atendimento a Refugiados na cidade de São Paulo

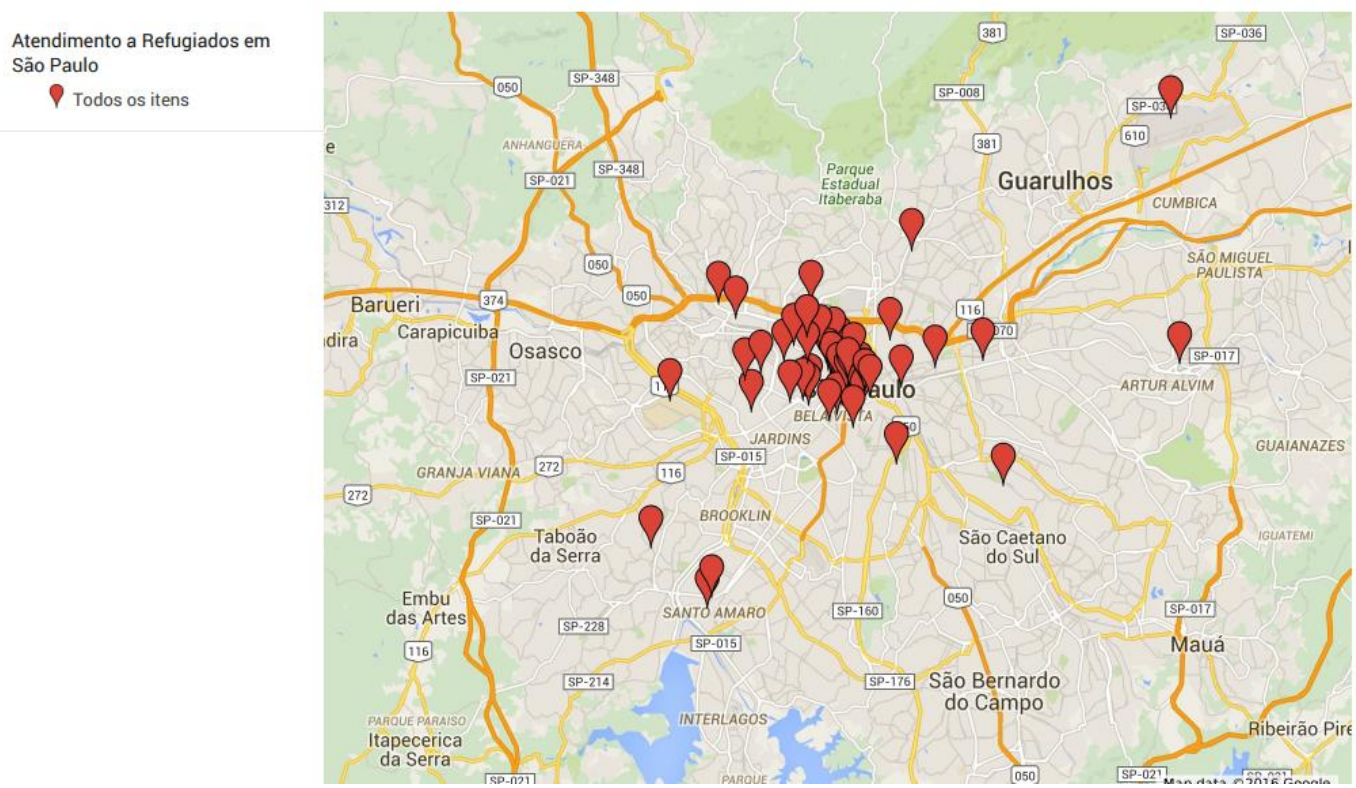


Fonte: elaborado pelas autoras.

Deste modo, apresentamos uma sinopse dos serviços oferecidos aos refugiados ou (i)migrantes na cidade de São Paulo e discorremos sobre a percepção dos entrevistados quanto à qualidade desses serviços. Embora estejamos tratando, em específico, os serviços da cidade de São Paulo constatamos que alguns dos refugiados entrevistados chegaram ao Brasil de navio, atracando no Porto de Belém ou Porto de Santos, por isso optamos por indicar o posto da Polícia Federal situado no porto.

\section{PERCEPÇÃO SOBRE OS SERVIÇOS OFERECIDOS/UTILIZADOS}

O primeiro aspecto abordado foi a questão da documentação, essa que é tão importante e essencial para garantia dos direitos aos refugiados. Constatou-se (Tabela 1) que todos os entrevistados tiveram acesso à Polícia Federal, assim como 11 deles foram atendidos na Receita Federal, a qual emite o Certificado de Pessoa Física (CPF), outros dois estiveram presentes no Centro de Apoio ao Trabalhador (CAT) e três utilizaram o Poupatempo.

Tabela 1 Perspectiva dos entrevistados quanto à emissão de documentação

\begin{tabular}{|c|c|c|c|c|c|c|c|c|}
\hline \multicolumn{2}{|r|}{ Serviço } & \multicolumn{4}{|c|}{ Atendentes Fluentes em outro Idioma } & \multicolumn{3}{|c|}{ Classificação do Serviço } \\
\hline \multirow{4}{*}{ 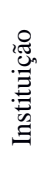 } & Polícia Federal & 24 & Sim & Não & Outros & $\mathrm{R}$ & $\mathrm{B}$ & $\mathrm{O}$ \\
\hline & Receita Federal & 11 & 5 & 13 & 6 & 1 & 21 & 2 \\
\hline & Centro de Apoio ao Trabalhador & 2 & & & & & & \\
\hline & Poupa Tempo & 3 & & & & & & \\
\hline
\end{tabular}

Quanto à fluência dos atendentes, seis declararam que foram atendidos por fluentes em seus idiomas, enquanto 13 não eram e seis afirmaram "outros", o que compreendemos que embora o atendente não pudesse ser considerado fluente houve o estabelecimento de algum tipo comunicação entre eles. Os refugiados classificaram esse tipo de serviço em sua maioria como bom, um deles denominou o serviço ruim e outros dois como ótimo. Cumpre mencionarmos que o participante que apontou o serviço como ruim referiu-se à Polícia Federal do Porto de Belém, PA, pois chegou ao país de navio. Percebemos pelos relatos que 
há um tipo de diferenciação entre as percepções nesse sentido, pois aqueles que entraram no Brasil por via aérea elogiaram - com mais ênfase - o serviço prestado pela Polícia Federal, o que por sua vez não ocorreu com os que chegaram de navio. Supomos que alguns fatores corroboram para essa percepção, um deles seria o cansaço do refugiado que passou semanas em alto mar, assim como chegam poucos ou quase nada nutridos ao país, ou seja, deduzimos que o elemento físico possa ter interferido na percepção do participante. Por outro lado, também supomos que o manejo dos atendentes nos aeroportos pode, de fato, ser melhor que nos Portos, uma vez que atendem um fluxo maior de pessoas e já estão habituados a receber imigrantes que vieram buscar refúgio.

Ficamos com a sensação pelos relatos que há um pré-julgamento em relação àqueles que chegam de navios, como se viessem escondidos, clandestinos, talvez pelo fato do custo de se chegar ao país de navio ser bem menor do que vir de avião. Essa situação nos remeteu, tristemente, ao cenário de escravidão, vivido outrora, no Brasil. Seria possível, mesmo que no imaginário social, associar esse fato com o transporte dos escravos? Essa inquietação pode ser explorada em outra pesquisa realizada apenas com refugiados que entraram no país de navio.

Concernente aos serviços de saúde, os participantes já utilizaram os seguintes: Sistema Único de Saúde; Unidade Básica de Saúde, AMA, Posto de Saúde e a Santa Casa. Antes de especificarmos os dados apresentados na Tabela 2, precisamos fazer um adendo quanto aos serviços utilizados: todos compõem o Sistema Único de Saúde, ou seja, notamos que boa parte dos entrevistados conhece o SUS, mas não possuem muitas informações quanto aos serviços que abrangem o Sistema, por isso citam os outros equipamentos sem fazer menção ao SUS.

Tabela 2 Perspectiva dos entrevistados quanto à prestação de serviços de Saúde

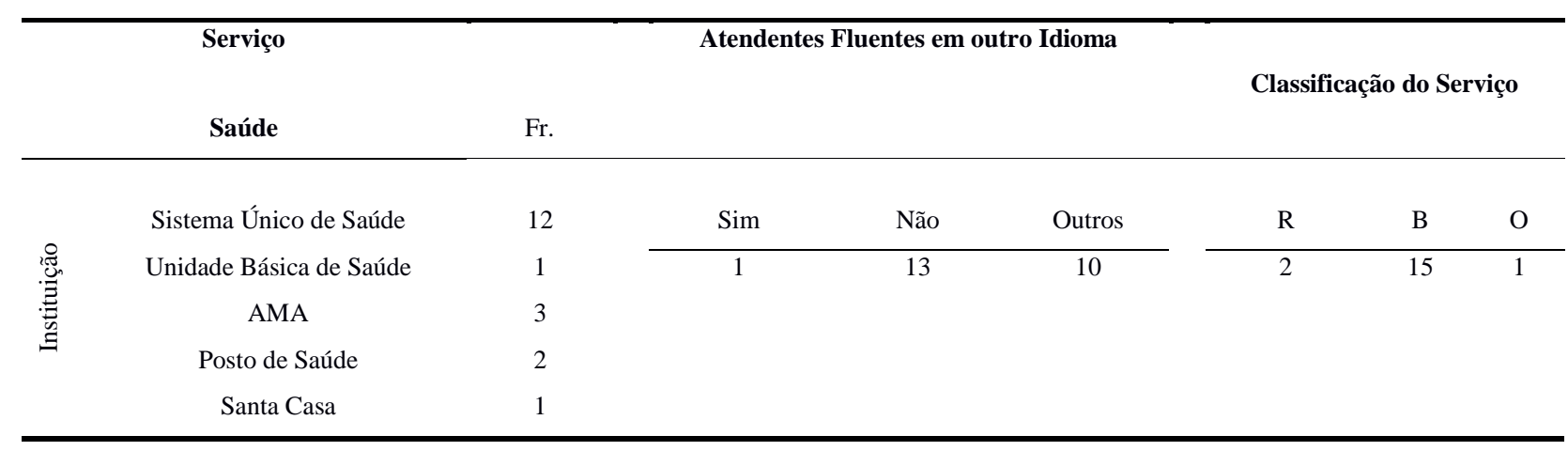


Constatamos dois pontos relevantes quanto ao atendimento no serviço de saúde, o primeiro refere-se ao fato que somente um dos entrevistados foi atendido por um fluente em seu idioma, enquanto 13 foram por não fluente e 10 citaram outros, o que novamente demonstra que a comunicação não ocorreu de modo fluído, isto é, essa comunicação pode ser por meio de gestos ou "mistura" de idiomas - com o atendente falando algumas palavras no idioma do entrevistado, mas sem estabelecer diálogo. Esse aspecto é significativo, pois imaginemos um atendimento num ambiente hospitalar onde não compreendem o que você está a dizer? Uma preocupação cabível, uma vez que a falta de compreensão entre as partes pode interferir e até alterar o diagnóstico.

O segundo ponto concernente à questão é que, mesmo não sendo a maioria dos atendentes fluentes no idioma do atendido, estes consideram o serviço oferecido bom. Um deles chegou a justificar que além de ser atendido sem custo ainda recebeu a medicação. Apesar das deficiências conhecidas do nosso Sistema de Saúde ele ainda é gratuito, o que para os refugiados é de suma importância e sem deixar de considerar a população brasileira.

Outro serviço que investigamos a percepção dos refugiados foi o trabalho, o qual não se centrou somente na questão se o mesmo estava ou não trabalhando, mas se estendeu aos serviços oferecidos que permitem acessibilidade ao trabalho, como exposto na Tabela 3.

Tabela 3 Perspectiva dos entrevistados quanto aos serviços relacionados ao acesso ao Trabalho

\begin{tabular}{|c|c|c|c|c|c|c|c|c|}
\hline \multicolumn{2}{|c|}{$\begin{array}{r}\text { Serviço } \\
\text { Trabalho }\end{array}$} & & \multicolumn{3}{|c|}{ Atendentes Fluentes em outro Idioma } & \multicolumn{3}{|c|}{ Classificação do Serviço } \\
\hline \multirow{4}{*}{ 葾 } & Poupatempo & 5 & Sim & Não & Outros & $\mathrm{R}$ & $\mathrm{B}$ & $\mathrm{O}$ \\
\hline & CIC Imigrante & 5 & 3 & 8 & 9 & 2 & 9 & 1 \\
\hline & CAT Luz & 3 & & & & & & \\
\hline & PAT & 1 & & & & & & \\
\hline
\end{tabular}

Dos participantes que utilizaram esse tipo de serviço, os locais frequentados foram: Poupatempo, CIC Imigrante, CAT Luz e o PAT. Novamente, evidenciamos que a maioria dos atendentes não são fluentes no idioma do atendido. Mencionamos que o número de indicação de fluência dos atendentes é superior ao número dos sujeitos, apenas porque alguns que não 
estão trabalhando ou não entraram em contato com alguns desses serviços de modo direto referiram-se á busca por emprego, ação qual efetuaram sem intervenção de uma instituição, por isso mencionam que quem os atenderam não eram fluentes em seu idioma. Nota-se quanto à classificação do serviço que dois dos participantes não especificaram seu grau de satisfação. Todavia, observamos que a maioria o classifica como bom.

Já, os serviços de ensino da língua portuguesa, um aspecto chamou nossa atenção, o número relativamente baixo de refugiados que fazem as aulas, isso considerando aqueles que não sabem português, ou seja, excluindo os angolanos que geralmente, mesmo que falem outros dialetos, possuem conhecimento do idioma português. A tabela 4, a seguir, traz os resultados quanto aos participantes que fazem aula de português.

Tabela 4 Perspectiva dos entrevistados quanto à prestação de serviços aulas de português

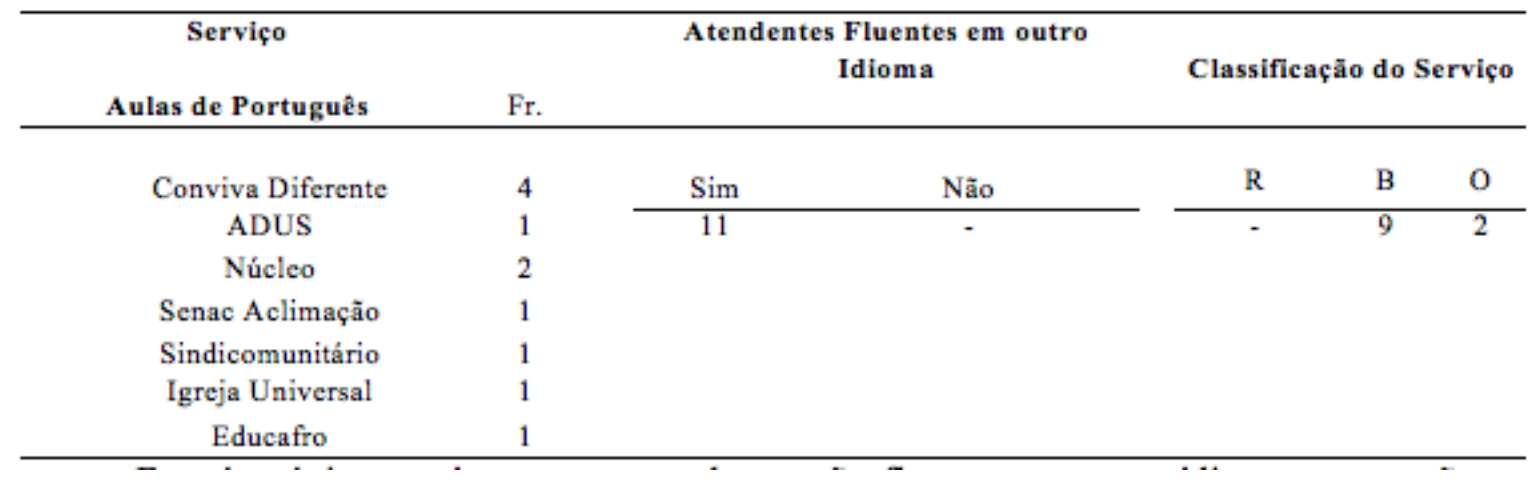

Este é o único serviço que os atendentes são fluentes em outro idioma, o que não poderia ser diferente, pois para ensinar os refugiados é necessário ter conhecimento em outro idioma para estabelecer formas de comunicação e de ensino. Os participantes classificam o serviço como bom ou ótimo.

Vamos destacar um ponto neste aspecto, pois percebemos pelo resultado do levantamento/mapeamento que há várias instituições, principalmente da sociedade civil que oferece curso gratuito de português, mas nem todos os refugiados procuram esses serviços de imediato. O que pode acontecer por dois motivos, como mencionamos no item sobre a moradia, os refugiados tendem a se agrupar em "guetos" onde a forma de comunicação é no seu idioma, assim não necessariamente estabelecem contato com outros brasileiros, para além daqueles que os atendem em algum serviço. Apesar de ser essencial os atendentes terem conhecimento em outro idioma defendemos também que, a adaptação do refugiado no país 
pode ser mais rápida, se o mesmo começar a aprender português o mais rápido possível. O outro motivo para a demora ou ausência pode estar associado à falta de informação, desconhecimento dos locais que ofertam o curso gratuitamente.

Por sua vez, com relação ao auxílio transporte, para deslocamento na cidade de São Paulo, seis participantes afirmaram receber auxílio, um devido ao vínculo empregatício, três deles recebem pelo Coletivo Conviva Diferente, um pela Soluções e o outro por conta de um curso de jardinagem. Têm-se, também, sete que declararam ser auxiliado por outras vias, o que nos leva a deduzir se tratar de auxílio de amigos ou custeio próprio. Assim como, somente três dos entrevistados recebem bolsa família (por intermédio do CRAI - entendemos que essa instituição que providenciou a obtenção do auxílio, por isso os entrevistados a citaram, pois o auxílio é proveniente de um Programa do Governo Federal), seis alegaram receber auxílio por outras vias e 15 não são auxiliados.

\section{CONSIDERAÇÕES FINAIS}

O presente estudo teve por objetivo delinear uma percepção acerca dos serviços oferecidos aos refugiados e/ou imigrantes na cidade de São Paulo. Buscou-se compreender a perspectiva desses sujeitos quanto aos serviços existentes. Conclui-se que a Polícia Federal foi considerada a instituição pública com melhor atendimento por quase metade dos participantes e um quarto considerou todos os serviços de boa qualidade. Mesmo naqueles muitos casos que afirmaram que, durante o atendimento, o serviço não dispunha de atendentes bilíngues, percebemos que no geral, os serviços foram bem avaliados porque cumpriram sua função prestativa e, por muitas vezes, acolhedora para aqueles que chegam ao nosso país em busca de refúgio. Quanto ao item referente ao atendimento em língua estrangeira, todos que utilizaram os serviços no SESC Carmo, ADUS e Coletivo Conviva Diferente responderam que os atendentes eram fluentes na língua do imigrante ou refugiado, ou seja, nesses locais há atendentes no mínimo bilíngues. Dos cinco entrevistados que usaram os serviços no Poupatempo, três responderam que os atendentes eram fluentes. Apesar do bom atendimento na Polícia Federal, a instituição não foi bem avaliada neste item, mas isso pode ser compensado na facilidade dos formulários disponíveis no idioma do solicitante de refúgio e na informação de que eles possuem fones com explicações em várias línguas.

Considerando-se o número total de atendimentos realizados aos entrevistados em cada uma das instituições públicas e organizações a seguir, também apresentaram boa avaliação: 
Receita Federal; Rede SUS; Cáritas; Missão Paz; CAT; Coletivo Conviva Diferente; ADUS; Poupatempo. A rede de equipamentos do SUS foi bem avaliada por oferecer atendimento e medicamentos gratuitos. As únicas três avaliações negativas foram com relação à demora no agendamento de consultas e exames, o que é perfeitamente compreensível como uma falha congênita do Sistema que assola a sociedade brasileira, em sua totalidade. A maior necessidade, indicada pelos entrevistados é a obtenção de emprego, mencionada por mais da metade deles. Seguido da necessidade de frequentar aulas de português e a obtenção de RNE. Além das citadas acima, no espaço destinado às observações, mencionaram as seguintes demandas: maior salário; oferta de ensino universitário; reconhecimento de diploma universitário; instituições bancárias terem conhecimento que protocolo de refúgio é válido para abertura de conta corrente; atendentes falarem inglês nas instituições públicas; publicidade na TV sobre serviços oferecidos no Brasil; divulgação de serviços nos meios de comunicação; entender quando brasileiros explicam as direções após serem questionados sobre onde fica um local; informações sobre moradia; valor mais baixo de aluguel; informações sobre bibliotecas e cinemas em praça pública; auxílio transporte; passagens com menor valor para o Haiti; curso de português próximo à residência; creche para filhos; facilitação do agendamento dos serviços, os quais são sempre burocráticos.

Importante salientar que, com relação ao trabalho, dos oito entrevistados que estão atualmente empregados, seis declararam que os empregos foram obtidos por intermédio de amigos ou, por conta própria, diretamente nos estabelecimentos. O que talvez indique que os PATs e CATs não estejam sendo efetivos em suas funções. Com relação aos Cursos profissionalizantes, Lazer/ Esportes e Cultura e obtenção de Bolsa Família, os entrevistados não possuem acesso às informações adequadas. Nos comentários apresentados, respectivamente, referente a cada item, foi verificado que os entrevistados gostariam, em relação aos Cursos Profissionalizantes de frequentar cursos de: enfermagem; paisagismo; eletricista; assistente administrativo; estética; curso na construção civil ou para trabalhar com empilhadeira; cursos relacionados à educação. Com relação a Lazer/Cultura/Esporte: informações sobre onde praticar esportes, tais como: futebol; artes marciais; basquetebol e o acesso às informações sobre atividades musicais. Quanto ao Programa Bolsa Família, apesar dos imigrantes e refugiados terem direito ao Programa, muitos desconhecem o serviço (15 entrevistados). Para ter esse direito é necessário apenas que o indivíduo se dirija ao Centro de Referência e Acolhida para Imigrantes - CRAI cadastre-se no Cadastro Único (CadÚnico). O 
auxílio transporte é um anseio de todos. Muitos deixam de frequentar cursos de português e praticar atividades de lazer, esportivas e culturais pela falta de recursos para tal.

Diferentemente de outros entrevistados, dois nigerianos, que chegaram ao Brasil de navio em Belém do Pará, relataram momentos de aflição e sofrimento até conseguirem acolhimento em São Paulo na Casa do Migrante. Ao chegarem a Belém do Pará, a Polícia Federal contou-lhes que não teriam condições de ficar na cidade, pois não havia abrigos nem empregos para eles. Dos quinze africanos, sete vieram para São Paulo. Os outros se separaram e, provavelmente, tiveram que voltar para seus países. Um dos nossos entrevistados tinha o contato de um amigo advogado brasileiro que os direcionou a Defensoria Pública da União (DPU) para resolver a situação. Por intermediação dos órgãos estadual e federal os dois rapazes conseguiram vagas para se abrigarem em São Paulo, na Missão Paz. Apesar do ocorrido, os dois mantinham certo otimismo e um deles fez uma das declarações mais tocantes que pudemos ouvir ao longo de todas as demais entrevistas: "O Brasil tem problemas econômicos agora, mas eles ajudam os imigrantes. Rezo para o governo brasileiro ter boas políticas econômicas para os imigrantes”.

Por fim, após estabelecer contato tão próximo aos refugiados e estar presente quase que diariamente na sua realidade só podemos esperar que os avanços se ampliem de modo a tornar o Brasil um país referência mundial pelo acolhimento ao refugiado e um exemplo pela possibilidade de devolver às pessoas o direito de sonhar e realizar seus desejos.

\section{REFERÊNCIAS BIBLIOGRÁFICAS}

ACNUR - AGÊNCIA NACIONAL DA ONU PARA REFUGIADOS. Refúgio no Brasil: uma análise estatística Janeiro de 2010 a Outubro de 2014. Disponível em: <http://www.acnur.org/t3/fileadmin/Documentos/portugues/Estatisticas/Refugio_no_Brasil_2 010_2014.pdf?view=>. Acesso em: 28 maio 2016.

ADUS - INSTITUTO DE REINTEGRAÇÃO DO REFUGIADO. Sobre nós: histórico. ADUS, 2015. Disponível em: <http://www.adus.org.br/sobre-nos/historico/>. Acesso em: 29 maio 2016.

AGÊNCIA NACIONAL DA ONU PARA REFUGIADOS - ACNUR. Refúgio no Brasil: uma análise estatística Janeiro de 2010 a Outubro de 2014. Brasil: Brasília, 2014. Disponível em:http://www.acnur.org/t3/fileadmin/Documentos/portugues/Estatisticas/Refugio_no_Brasil _2010_2014.pdf?view=1. Acesso em: 28 maio 2016. 
BRASIL. O que é a Convenção de 1951? ACNUR. Brasil, 2016. Disponível em: $<$ http://www.acnur.org/portugues/informacao-geral/o-que-e-a-convencao-de-1951/>. Acesso em: 02 julho 2016.

CARITAS. O Centro de Referências para Refugiados. Caritas Arquidiocesana de São Paulo, 2014. Disponível em: <http://www.caritassp.org.br/?page_id=85>. Acesso em: 29 maio 2016.

CONVENÇÃO RELATIVA AO ESTATUTO DOS REFUGIADOS. Nações Unidas: ONU, ACNUR.

<http://www.acnur.org/t3/fileadmin/Documentos/portugues/BDL/Convencao_relativa_ao_Est atuto_dos_Refugiados.pdf?view=1>. Acesso em: 20 maio 2016.

DALFOVO, M. S.; LANA, R. A.; SILVEIRA, A. Métodos quantitativos e qualitativos: um resgate teórico. Revista Interdisciplinar Científica Aplicada, Blumenau, v.2, n.4, p.1- 13, 2008.

Disponível

em:

<http://www.unisc.br/portal/upload/com_arquivo/metodos_quantitativos_e_qualitativos_um_r esgate_teorico.pdf>. Acesso em: 02 jul. 2016.

ENOUGH PROJECT 2009. Eastern Congo. Disponível em: $<$ http//www.enoughproject.org/conflicts/eastern_congo> Acesso em:10 jul. 2016 .

IBGE - INSTITUTO BRASILEIRO DE GEOGRAFIA E ESTATÍSTICA. Censo Demográfico 2010: resultados gerais da amostra. Rio de Janeiro, 2012, p. 1-65. Disponível em:<http://www.ibge.gov.br/home/presidencia/noticias/imprensa/ppts/000000084731041220 12315727483985.pdf>. Acesso em: 24 maio 2016.

NÚMERO DE IMIGRANTES cresceu 86,7\% em dez anos no Brasil, diz IBGE. G1, Brasil, 27 abr. 2012. Disponível em: <http://g1.globo.com/brasil/noticia/2012/04/numero-de-imigrantes-cresceu-867em-dez-anos-no-brasil-diz-ibge.html>. Acesso em: 20 maio 2016.

OCDE - ORGANIZAÇÃO PARA A COOPERAÇÃO E O DESENVOLVIMENTO ECONÔMICO. Migração Mundial em números: uma contribuição conjunta do UNDESA e da OCDE para o Diálogo de Alto Nível das Nações Unidas sobre Migração e Desenvolvimento, 3 e 4 de outubro de 2013. OECD-UNDESA, 2013, p. 1-6. Disponível em: <https://www.oecd.org/els/mig/PORTUGUESE.pdf>. Acesso em: 26 maio 2016.

PASSARINHO, N. Pedidos de refúgio no Brasil crescem 930\% de 2010 a 2013, diz Acnur. G1, Mundo, 18 nov. 2014, Brasília. Disponível em: < http://glo.bo/1yhTSTt>. Acesso em: 22 maio 2016.

PORTAL DA PREFEITURA DE SÃO PAULO. Coordenação de Políticas para Migrantes. Apresentação: Centro de Referência e Acolhida para o Imigrante. São Paulo, 2015. 
Disponívelem:http://www.prefeitura.sp.gov.br/cidade/secretarias/direitos_humanos/migrantes /crai/index.php?p=186973. Acesso em: 29 maio 2016. 